\title{
Prevalence of White Spot Lesions in 3-year-old Children Visiting a Private Dental College: An Observational Study
}

\author{
Maria Anthonet Sruthi ${ }^{1}$, Deepa Gurunathan ${ }^{2}$, Vignesh Ravindran ${ }^{3}$
}

\begin{abstract}
Aim: The present study aimed to evaluate the presence of white spot lesions in 3-year-old children visiting a private dental institution and belonging to the Chennai population.

Materials and methods: A total of 165 patients and 990 teeth were reviewed for white spot lesions using photographs obtained after reviewing case sheets. The data extracted were analyzed using descriptive statistics on SPSS software.

Results: The highest percentage of lesions was present in the maxillary right and left canines and was 78 and $67.7 \%$, respectively, and the least was observed in mandibular right and left central incisors namely 9.2 and $5.5 \%$.

Conclusion: The prevalence of white spot lesions was maximum in maxillary canines and the least was observed in mandibular incisors in 3-year-old children visiting a private dental college in Chennai.

Clinical significance: Early detection and intervention of white spot lesions can minimize the symptoms associated with early childhood caries, thereby halting its progression.

Keywords: Early childhood caries, Early enamel lesions, Primary dentition, Retrospective study, White spots.

World Journal of Dentistry (2020): 10.5005/jp-journals-10015-1759
\end{abstract}

\section{INTRODUCTION}

Early childhood caries (ECC) is one of the ubiquitous chronic diseases affecting young children. It significantly affects both well developed and industrial nations. ${ }^{1}$ According to the American Academy of Pediatric Dentistry, ECC may be defined as the presence of one or more decayed (cavitated and non-cavitated lesions), missing (due to caries), or filled tooth surfaces in any primary teeth in a child 71 months of age or younger. ${ }^{2}$ Early childhood caries is a universal and multifactorial disease with over 1.76 billion cases. ${ }^{3}$ Even though the decay-missing-filled-teeth (DMFT) count had been downsliding over the past years, its prevalence has not. ${ }^{4}$ In India, the prevalence figure is $44 \%$ in $8-48$ months old children. ${ }^{5}$ In rural South India, the prevalence rate among $0-3$ years old is $40.6 \%$. Of these, $50.3 \%$ were associated with non-cavitated lesions and $49.7 \%$ showed cavitated surfaces. ${ }^{6}$ The prevalence of ECC in Tamil Nadu, India was $15.9 \%$ as of $2015 .^{7}$

Due to its rapid development, young enamel is often thin and has less organized structure. ${ }^{8}$ Hence, acids are able to demineralize deciduous enamel in an unrestrained manner resulting in ECC. ${ }^{9}$ This collides with the quality of life of children as it may lead to pain, swelling, infection, and other symptoms. ${ }^{10,11}$

The initial stage of demineralization results in white chalky appearance on the teeth, these are called white-spot lesions (or) incipient lesions (or) surface softened defect. ${ }^{12,13}$ White spot lesion implies that there is a subsurface area with mineral loss beneath a relatively intact enamel surface. ${ }^{14}$ Clinically, early caries lesion is seen as a white opaque spot, characterized by being softer than the adjacent enamel and increasingly whiter when dried with air. It affects all parts of the tooth including the smooth surface. They are usually found along the gumline. White spot lesions can be actively demineralizing or remineralizing or arrested. ${ }^{15}$

It is acknowledged that the subsurface damage may be due to acid formed from plaque on the tooth surface. ${ }^{16}$ The organic
${ }^{1-3}$ Department of Pediatric and Preventive Dentistry, Saveetha Dental College and Hospitals, Saveetha Institute of Medical and Technical Sciences, Saveetha University, Chennai, Tamil Nadu, India

Corresponding Author: Deepa Gurunathan, Department of Pediatric and Preventive Dentistry, Saveetha Dental College and Hospitals, Saveetha Institute of Medical and Technical Sciences, Saveetha University, Chennai, Tamil Nadu, India, Phone: +91 9994619386, e-mail: deepag@saveetha.com

How to cite this article: Sruthi MA, Gurunathan D, Ravindran V. Prevalence of White Spot Lesions in 3-year-old Children Visiting a Private Dental College: An Observational Study. World J Dent 2020;11(5):408-412.

Source of support: Nil

Conflict of interest: None

acids produced by bacteria enter the interprismatic spaces of enamel and cause dissolution of apatite crystals, calcium and phosphate ions, and demineralization. ${ }^{17}$ These white spot lesions inevitably develop into lesions with cavitations if the mineral loss continues. ${ }^{18}$ However, according to the caries balance concept ${ }^{19}$ the factors of demineralization can be counteracted by the factors of remineralization of which saliva and its components play a major role. Recently, biomarkers present in saliva can help detect the formation of caries. ${ }^{20}$

Conversely, ECC is a multifactorial disease which is substantially associated with parental attitude toward dental caries in primary dentition. ${ }^{21}$ Management and maintenance of the advanced lesions mainly include operative methods. ${ }^{22-28}$ Prophylactic methods are obligatory in order to control and overcome the consequences of the disease. ${ }^{29-31}$

Minimum literature is available on white spot lesions in primary dentition. Only one other study attempted to determine the prevalence of white spots by evaluating the contribution 
of biological and socioeconomic variables. ${ }^{32}$ Because ECC is considered as a public health problem, the need to know its prevalence is justified. However, it must include information about all stages of formation and occurrence in different populations. ${ }^{33}$

Therefore, the aim of this study is to assess the presence of white spot lesions in 3-year-old children visiting a private dental institution and those belonging to the Chennai population.

\section{Materials and Methods}

The observational study was conducted in the Department of Pediatric and Preventive Dentistry in a private Dental Institute in Chennai during the period of June 2019 to March 2020. The ethical approval for this preliminary study was obtained from the Institutional Ethical committee (SDC/SIHEC/2020/ DIASDATA/0619-0320). Written informed consent was obtained from the parents of the participating children after explaining to them the need of the study.

Healthy children of 3 years of age visiting the pediatric dental department were included in the study. In order to avoid sampling bias, the recruitment of the children was performed through simple randomization. Children with preexisting medical conditions and those with special needs were excluded from the study.

The children participating in the study were seated on the dental chair and supragingival scaling was carried out to remove plaque and debris. Post-scaling, photographs of their dentition were taken to assess the white spot lesions. A digital camera namely Canon 1500D with Tamron $90 \mathrm{~mm}$ macro lens, specifications of $1 / 200$ shutter speed, and iOS $100 \mathrm{f}-20$ was used for this purpose. After adequate drying of the teeth and placement of cheek retractor, photographs were taken from different angles namely intraoral frontal, intraoral right, and intraoral left. Superior and inferior angles were taken using pedosized intraoral mirror. All photographs were taken under a single light source, so that the detection and appearance of white spot lesions would be uniform.

The data verification, collection, and analysis were carried out by two persons by reviewing 86,000 case sheets. Of which, records pertaining to 3 -year-old children were obtained for the purpose of this study. The data were extracted by analyzing the photographs of the study participants. Five angles of the photograph were available for a single individual. The presence of white spot lesions was observed exclusively on the anterior teeth of the maxillary and mandibular arch by reviewing from various angles. They were detected according to International Caries Detection and Assessment System (ICDAS) II criteria, code 1: first visual change in enamel. Any dispute over detection was analyzed and resolved by a third reviewer. The internal validity was high as it was a representative sample and the external validity was high as the study results may be generalized to the Chennai population.

The collected data were tabulated into Excel Sheet and imported to Statistical Package for Social Sciences software by IBM for data analysis. A total of 165 study participants and 990 teeth were assessed for white spot lesions. Descriptive statistical analysis was performed and the results were tabulated graphically based on the presence and absence of white spots and carious lesions on each of the upper and lower anterior teeth of the primary dentition. Chisquare test was performed to associate the relationship between the presence of white spot lesions and gender.

\section{Results}

The study was performed to evaluate the prevalence of white spot lesions in anterior teeth of 3-year-old children. A total of 165 participants were included and 990 teeth were assessed. The participants included 79 boys (47.6\%) and 86 girls (52.4\%) (Fig. 1). Of the 990 teeth assessed, the presence of white spot lesions in maxillary arch was 11 and $18.9 \%$ in right and left central incisors, 39 and $37.2 \%$ in right and left lateral incisors, and 78 and $67.7 \%$ in right and left canines. In the mandibular arch, 5.5 and $9.2 \%$ in right and left central incisors, 13.4 and $14 \%$ in right and left lateral incisors, 52.4 and $54.9 \%$ in right and left canines (Table 1). The lesions were highly prevalent in the maxillary canines in females (Fig. 2) followed by mandibular canines (Fig. 3) and the least were observed in mandibular central incisors (Fig. 4).

\section{Discussion}

White spot lesions are characterized by subsurface demineralization with an intact surface layer of enamel. Enamel defects and white lesions in deciduous incisors and molars may be attributed to coeliac disease (or) molar incisor hypoplasia. ${ }^{34}$

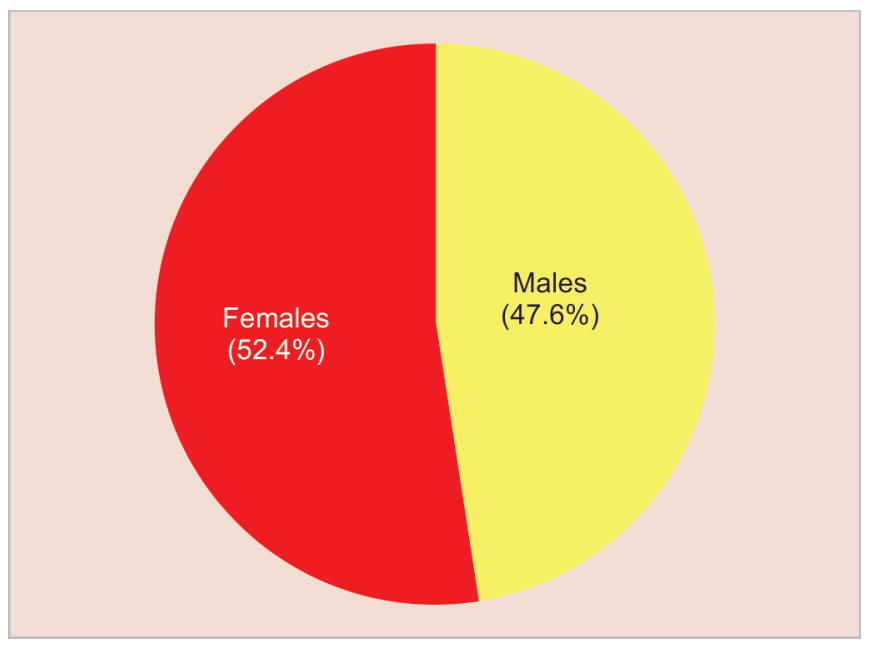

Fig. 1: The pie chart represents the distribution of the study participants by gender

Table 1: Represents the percentage distribution of carious lesions, presence and absence of white spot lesions on the right and left quadrants of deciduous anterior teeth on 3-year-old children

\begin{tabular}{lllll}
\hline $\begin{array}{l}\text { Deciduous } \\
\text { anterior teeth }\end{array}$ & Quadrant & Carious (\%) & WSL (\%) & WSL (\%) \\
\hline $\begin{array}{l}\text { Maxillary central } \\
\text { incisors }\end{array}$ & Right/left & $64.6 / 40.2$ & $11 / 18.9$ & $24.4 / 40.9$ \\
$\begin{array}{l}\text { Maxillary lateral } \\
\text { incisors }\end{array}$ & Right/left & $35.4 / 36$ & $39 / 37.2$ & $25.6 / 26.8$ \\
$\begin{array}{l}\text { Maxillary canines } \\
\begin{array}{l}\text { Mandibular } \\
\text { central incisors }\end{array}\end{array}$ & Right/left & $9.8 / 15.9$ & $78 / 67.7$ & $12.2 / 16.5$ \\
$\begin{array}{l}\text { Mandibular } \\
\text { lateral incisors }\end{array}$ & Right/left & 3.4 & $9.2 / 9.2$ & $87.7 / 91.5$ \\
$\begin{array}{l}\text { Mandibular } \\
\text { canines }\end{array}$ & Right/left & $9.8 / 9.8$ & $14 / 13.4$ & $83.5 / 83.5$ \\
\hline
\end{tabular}




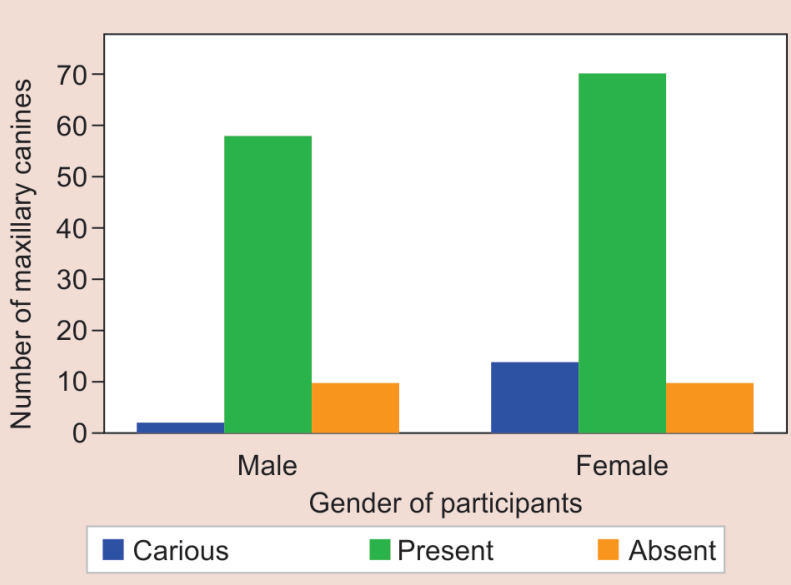

Fig. 2: Represents the association between gender and the presence of white spot lesions on primary maxillary canines. $X$-axis represents gender. $Y$-axis represents the number of maxillary canines observed and is depicted as carious involvement (blue), presence of white spot lesions (green), and absence of white spot lesions (orange). $p$ value $=$ $0.046^{\mathrm{a}} ; \mathrm{a}$, represents statistical significance on comparison

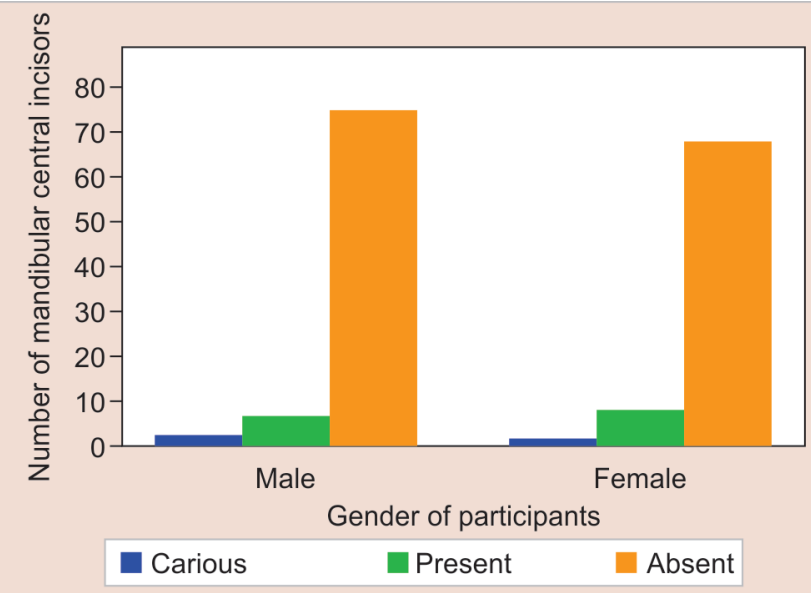

Fig. 4: Represents the association between gender and the presence of white spot lesions on primary mandibular central incisors. $X$-axis shows gender. $Y$-axis represents the number of mandibular central incisors observed and is depicted as carious involvement (blue), presence of white spot lesions (green), and absence of white spot lesions (orange). $p$ value $=0.08^{c} ; c$, represents statistical significance on comparison

When the demineralization-remineralization cycle is tipped off due to extrinsic factors associated with environment or intrinsic factors associated with the host, ${ }^{34}$ there is disruption in the maintenance of a neutral $\mathrm{pH}$ in the oral cavity resulting in early lesion formation (white spots) leading to cavitations and total destruction if unintervened.

Histopathologically, the enamel lesions are characterized by four histopathological zones namely two demineralization zones, such as translucent zones and body of the lesion, and two remineralization zones namely the dark zone and the surface zone. ${ }^{35}$ The translucent zone is the advancing front of the lesion with the dark zone superficial to it. The surface zone is the intact surface above the body of the lesion zone which lies 15-20 $\mu \mathrm{m}$ beneath the intact enamel. ${ }^{36}$ The reason for the surface to remain

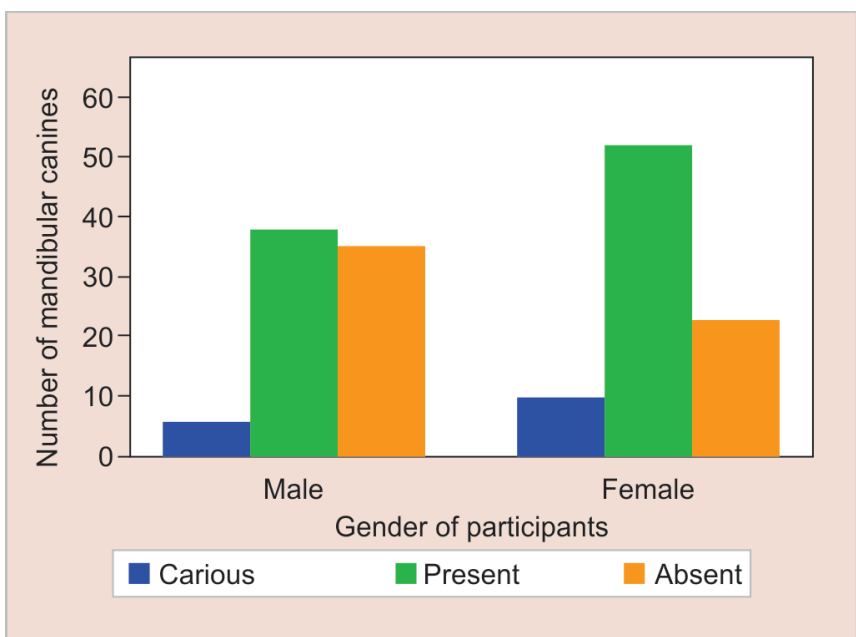

Fig. 3: Represents the association between gender and the presence of white spot lesions on primary mandibular canines. $X$-axis represents gender. $Y$-axis represents the number of mandibular canines observed and is depicted as carious involvement (blue), presence of white spot lesions (green), and absence of white spot lesions (orange). $p$ value $=$ $0.025^{\mathrm{b}}$; b, represents statistical significance on comparison

intact is because the calcium and the phosphate ions produced from subsurface dissolution move outward and reprecipitate on the surface. ${ }^{37}$

Since formation of dental caries in children proceeds in a short and rampant fashion even as early as 4 weeks due to the structural morphology of the primary tooth, there is no dark zone formation. Its prime function is to act as a barrier to the caries progression toward the dentin and subsequently to the pulp. Hence, a heavily demineralized body of lesion and a surface zone with minimal thickness is formed. ${ }^{33}$ Such a lesion becomes clinically detectable as white spots. The enamel is porous in the body of the lesion due to loss of minerals in the body of the lesion. Hence, there is an alteration of the refractive index in-between the translucent enamel crystals and the porous enamel resulting in a greater visual enamel opacity. ${ }^{17,38}$

In our study, assessment of white spot lesions was carried out through photographic analysis. Many studies have assessed enamel defects through this method and hence this was followed as a reliable method. ${ }^{39,40}$ Photographic methods can be advantageous for epidemiological studies. In addition, it allows for blinded assessment to avoid examiners bias. ${ }^{41}$

The 165 study participants included $47.6 \%$ of males and females $52.4 \%$ of 3 years of age. Among the 990 teeth assessed for white spot lesions, the prevalence in descending order is maxillary canines $>$ mandibular canines $>$ maxillary lateral incisors $>$ maxillary central incisors $>$ mandibular incisors.

Maxillary canines (78 and 67.7\%) showed the maximum white spot lesions and mandibular central incisors (9.2 and 5.5\%) showed the least lesions. This can be made concurrent with the development of ECC lesions which is highest in maxillary anteriors and the lowest in the mandibular incisors. ${ }^{42}$ The caries lesion is generally first seen on the primary maxillary incisors and the four maxillary anteriors are often involved concurrently. ${ }^{43}$ This is evident in our study where cavitations had already occurred in maxillary central incisors at the time of assessment (64.6 and 40.2\%).

According to a study by Ramos-Gomez et al., the boys were significantly more affected than the girls. ${ }^{44}$ This was contradicting 
in our study as females showed a slightly greater prevalence of white spot lesions. At the specified age group, high prevalence of white spots was observed in accordance to a study by Tiano et al. ${ }^{32}$ Previous literature reveals higher prevalence figures of subsequent ECC for 3-year olds which ranges from 36 to $85 \% .{ }^{45,46}$

The prevalence of white spot lesions has been reported to range from 2 to $96 \% .{ }^{47}$ However, no studies were found in literature regarding the prevalence of white spot lesions in preschool children in the Indian population.

Every study presents itself with certain limitations. Similarly, the current study was a preliminary attempt on evaluating the prevalence of white spots in the primary teeth only through photographic evaluation whereas direct observation and assessment of lesions was not carried out. The results were not compared with other diagnostic methods, such as dyes, fluorescent methods, and DIAGNOdent. Also, no association was made with diet, oral hygiene practices, socioeconomic status, and fluoride exposure.

The scope of the study focuses on the arena that early detection of such lesions by clinicians helps to provide parental education and awareness on the progress of the lesions. It can also lead to utilization of preventive and interventional materials and methods.

\section{Conclusion}

Within the limits of the study, it can be concluded that the prevalence of white spot lesions was maximum in maxillary canines and the least was observed in mandibular incisors in 3-year-old children visiting a private dental college in Chennai. Early detection and intervention of white spot lesions can minimize the symptoms associated with ECC, thereby halting its progression and other financial and psychological outcomes associated with it.

\section{Acknowledgments}

I would like to extend my sincere gratitude and appreciation to $\mathrm{Dr}$ Deepa $G$ and Dr Vignesh R for their contributions and for guiding me in this study.

\section{References}

1. Alazmah A. Early childhood caries: a review. J Contemp Dent Pract 2017;18(8):732-737. DOI: 10.5005/jp-journals-10024-2116.

2. American Dental Association Statement on Early Childhood Caries [Internet]. 2019 [cited 2020 Jun 7]. Available from: 2. American Dental Association Statement on Early Childhood Caries. Available at: https://www.ada.org/en/about-the-ada/ada-positions-policiesand-statements/statement-on-early-childhood-caries.

3. Huang $Y, X u X$. Faculty opinions recommendation of global, regional, and national incidence, prevalence, and years lived with disability for 328 diseases and injuries for 195 countries, 1990-2016: a systematic analysis for the global burden of disease study 2016. Lancet 2020.

4. Splieth $\mathrm{CH}$, Santamaria RM, Basner R, et al. 40 Year longitudinal caries development in German adolescents in the light of new caries measures. Caries Res 2019;53(6):609-616. DOI: 10.1159/000501263.

5. Bhayade SS, Mittal R, Chandak S, et al. Assessment of social, demographic determinants and oral hygiene practices in relation to dental caries among the children attending Anganwadis of Hingna, Nagpur. J Indian Soc Pedod Prev Dent 2016;34(2):124-127. DOI: 10.4103/0970-4388.180415.

6. Henry JA, Muthu MS, Saikia A, et al. Prevalence and pattern of early childhood caries in a rural south Indian population evaluated by ICDAS with suggestions for enhancement of ICDAS software tool. Int J Paediatr Dent 2017;27(3):191-200. DOI: 10.1111/ipd.12251.
7. Krishnan R, Kumar V, Ramesh M, et al. Prevalence of early childhood caries and its risk factors in 18-72 month old children in Salem, Tamil Nadu. J Int Soc Prev Community Dent 2015;5:95-102. DOI: 10.4103/2231-0762.155731.

8. Lucchese A, Storti E. Morphological characteristics of primary enamel surfaces vs permanent enamel surfaces: SEM digital analysis. Eur J Paediatr Dent 2011;12(3):179-183.

9. Zamudio-Ortega CM, Contreras-Bulnes R, Scougall-Vilchis RJ, et al. Morphological, chemical and structural characterisation of deciduous enamel: SEM, EDS, XRD, FTIR and XPS analysis. Eur J Paediatr Dent 2014;15(3):275-280.

10. Christabel SL, Gurunathan D. Prevalence of type of frenal attachment and morphology of frenum in children, Chennai, Tamil Nadu. World J Dent 2015;6(4):203-207. DOI: 10.5005/jp-journals-10015-1343.

11. Ravikumar D, Jeevanandan G, Subramanian EMG. Evaluation of knowledge among general dentists in treatment of traumatic injuries in primary teeth: a cross-sectional questionnaire study. Eur J Dent 2017;11(2):232-237. DOI: 10.4103/ejd.ejd_357_16.

12. Koulourides T, Feagin F, Pigman W. Remineralization of dental enamel by saliva in vitro. Ann N Y Acad Sci 1965;131(2):751-757.

13. Schweizer-Hirt CM, Schait A, Schmid R, et al. Erosion and abrasion of the dental enamel. Experimental study. SSO Schweiz Monatsschr Zahnheilkd 1978;88(5):497-529.

14. Welbury R, Duggal MS, Hosey MT. Paediatric Dentistry. Oxford University Press; 2012. p. 400.

15. Berkowitz RJ. Causes, treatment and prevention of early childhood caries: a microbiologic perspective. J Can Dent Assoc 2003;69(5):304307.

16. Arends J, Christoffersen J. The nature of early caries lesions in enamel. J Dent Res 1986;65(1):2-11. DOI: 10.1177/00220345860650010201.

17. Summitt JB. Fundamentals of Operative Dentistry: A Contemporary Approach. Quintessence Publishing Company; 2006. p. 599.

18. Ferreira MAF, Mendes NS. Factors associated with active white enamel lesions. Int J Paediatr Dent 2005;15(5):327-334. DOI: 10.1111/j.1365263X.2005.00641.x.

19. Featherstone JDB. The caries balance: the basis for caries management by risk assessment. Oral Health Prev Dent 2004;2(Suppl 1):259-264.

20. Subramanyam D, Gurunathan D, Gaayathri R, et al. Comparative evaluation of salivary malondialdehyde levels as a marker of lipid peroxidation in early childhood caries. Eur J Dent 2018;12(1):67-70. DOI: 10.4103/ejd.ejd_266_17.

21. Gurunathan D, Shanmugaavel A. Dental neglect among children in Chennai. J Indian Soc Pedod Prev Dent 2016;34(4):364. DOI: 10.4103/0970-4388.191420.

22. Jeevanandan G. Kedo-S paediatric rotary files for root canal preparation in primary teeth-case report. J Clin Diagn Res 2017;11(3):ZR03-ZR05.

23. Govindaraju L, Jeevanandan G, Subramanian EMG. Comparison of quality of obturation and instrumentation time using hand files and two rotary file systems in primary molars: a single-blinded randomized controlled trial. Eur J Dent 2017;11(3):376-379. DOI 10.4103/ejd.ejd_345_16.

24. Govindaraju L, Jeevanandan G, Subramanian EMG. Knowledge and practice of rotary instrumentation in primary teeth among indian dentists: a questionnaire survey. J Int Oral Health 2017:9(2):45-48. DOI: 10.4103/jioh.jioh_4_17.

25. Govindaraju L, Jeevanandan G, Subramanian E. Clinical evaluation of quality of obturation and instrumentation time using two modified rotary file systems with manual instrumentation in primary teeth. $J$ Clin Diagn Res 2017;11(9):ZC55-ZC58.

26. Jeevanandan G, Govindaraju L. Clinical comparison of kedo-S paediatric rotary files vs manual instrumentation for root canal preparation in primary molars: a double blinded randomised clinical trial. Eur Arch Paediatr Dent 2018;19(4):273-278. DOI: 10.1007/s40368018-0356-6.

27. Nair M, Jeevanandan G, Vignesh R, et al. Comparative evaluation of post-operative pain after pulpectomy with k-files, kedo-s files and 
mtwo files in deciduous molars-a randomized clinical trial. Braz Dent Sci 2018;21:411. DOI: 10.14295/bds.2018.v21i4.1617.

28. Panchal V, Jeevanandan G, Subramanian E. Comparison of instrumentation time and obturation quality between hand $\mathrm{K}$-file, $\mathrm{H}$-files, and rotary kedo-S in root canal treatment of primary teeth: a randomized controlled trial. J Indian Soc Pedod Prev Dent 2019;37(1):75-79. DOI: 10.4103/JISPPD.JISPPD_72_18.

29. Somasundaram S, Ravi K, Rajapandian K, et al. Fluoride content of bottled drinking water in Chennai, Tamil Nadu. J Clin Diagn Res 2015;9(10):ZC32-ZC34.

30. Govindaraju L, Gurunathan D. Effectiveness of chewable tooth brush in children-a prospective clinical study. J Clin Diagn Res 2017;11(3):ZC31-ZC34.

31. Ramakrishnan M, Bhurki M. Fluoride, fluoridated toothpaste efficacy and its safety in children-review. Int J Pharm Res 2018;10(04): 109-114.

32. Tiano AVP, Moimaz SAS, Saliba O, et al. Prevalence of enamel white spots and risk factors in children up to 36 months old. Braz Oral Res 2009;23(2):215-222. DOI: 10.1590/S1806-83242009000200020.

33. Bönecker M, Ardenghi TM, Oliveira LB, et al. Trends in dental caries in 1- to 4-year-old children in a Brazilian city between 1997 and 2008. Int J Pediatr Dent 2010;20(2):125-131. DOI: 10.1111/j.1365263X.2009.01030.x.

34. Anand V, Arumugam SB, Manoharan V, et al. Is resin infiltration a microinvasive approach to white lesions of calcified tooth structures? a systematic review. Int J Clin Pediatr Dent 2019;12(1):53-58. DOI: 10.5005/jp-journals-10005-1579.

35. Packiri S, Gurunathan D, Selvarasu K. Management of paediatric oral Ranula: a systematic review. J Clin Diagn Res 2017;11(9): ZE06-ZE09.

36. Pathak S, Roopa K, Poornima P, et al. White spot lesions: a literature review. J Pediatr Dent 2015;3(1).

37. Fejerskov O, Kidd E. Dental Caries: The Disease and Its Clinical Management. John Wiley and Sons; 2009. p. 640.
38. Gorelick L, Geiger AM, Gwinnett AJ. Incidence of white spot formation after bonding and banding. Am J Orthod 1982;81(2):93-98. DOI: 10.1016/0002-9416(82)90032-X.

39. Wong HM, McGrath C, Lo ECM, et al. Photographs as a means of assessing developmental defects of enamel. Community Dent Oral Epidemiol 2005;33(6):438-446. DOI: 10.1111/j.16000528.2005.00245.x.

40. Beerens MW, Boekitwetan F, van der Veen MH, et al. White spot lesions after orthodontic treatment assessed by clinical photographs and by quantitative light-induced fluorescence imaging: a retrospective study. Acta Odontol Scand 2015;73(6):441-446. DOI: 10.3109/00016357.2014.980846.

41. Elfrink MEC, ten Cate JM, Jaddoe VWV, et al. Deciduous molar hypomineralization and molar incisor hypomineralization. J Dent Res 2012;91(6):551-555. DOI: 10.1177/0022034512440450.

42. Yadav PK. Prevalence and association of developmental defects of enamel with, dental-caries and nutritional status in pre-school children, Lucknow. J Clin Diagn Res 2015;9(10):ZC71-ZC74.

43. Petti S, Cairella G, Tarsitani G. Rampant early childhood dental decay: an example from Italy. J Public Health Dent 2000;60(3):159-166. DOI: 10.1111/j.1752-7325.2000.tb03322.x.

44. Ramos-Gomez FJ, Weintraub JA, Gansky SA, et al. Bacterial, behavioral and environmental factors associated with early childhood caries. J Clin Pediatr Dent 2002;26(2):165-173.

45. Tsai Al, Chen CY, Li LA, et al. Risk indicators for early childhood caries in Taiwan. Community Dent Oral Epidemiol 2006;34(6):437-445. DOI: 10.1111/j.1600-0528.2006.00293.x.

46. Cariño KMG, Shinada K, Kawaguchi Y. Early childhood caries in northern Philippines. Community Dent Oral Epidemiol 2003;31(2): 81-89. DOI: 10.1034/j.1600-0528.2003.00010.x.

47. Øgaard B, Rølla G, Arends J, et al. Orthodontic appliances and enamel demineralization part 2. Prevention and treatment of lesions. Am J Orthod Dentofacial Orthop 1988;94(2):123-128. DOI: 10.1016/08895406(88)90360-5. 